\title{
A different etiology of pneumothorax: Truck tire explosion!
}

\author{
Baris Hekimoglu ${ }^{1(\underline{I D})}$ \\ ${ }^{1}$ Department of Thoracic Surgery, Faculty of Medicine, Ordu University, Ordu, Turkey
}

Copyright@ Author(s) - Available online at https://dergipark.org.tr/en/pub/mbsjohs

Content of this journal is licensed under a Creative Commons Attribution-NonCommercial 4.0 International

License,

Received: 22April 2021, Accepted: 09 August 2021, Published online: 31 August 2021

(C) Ordu University Institute of Health Sciences, Turkey, 2021

\begin{abstract}
A Pneumothorax (PNX) is the accumulation of air in the pleural space. PNX, which occurs due to the blast effect of an intense explosion, is a rare and important cause in etiology, as it is generally seen as spontaneous PNX. Blast injuries have become more common in the last century causing by terrorist attack events like bomb explosions and home-related or industrial accidents. While repairing or servicing a large tire, the explosion of the tire may result in high mortality and morbidity. In this case report, we present a 37-year-old male truck driver with barotraumatic PNX and rib fractures that developed due to a truck tire explosion.
\end{abstract}

Key words: Blast injuries, pneumothorax, tire, trauma

Suggested Citation: Hekimoglu B. A different etiology of pneumothorax: Truck tire explosion! Mid Blac Sea Journal of Health Sci, 2021; 7(2):304-307

\section{Address for correspondence/reprints:}

Barış Hekimoğlu

Telephone number: +90 (505) 7510689

E-mail: drbarishekimoglu@yahoo.com 


\section{Introduction}

A Pneumothorax (PNX) is the accumulation of air in the pleural space. PNX occurs when air accumulates between the visceral and parietal pleura inside the thorax. This increased air pressure makes the lung collapsed $(1,2)$. Generally, PNX occurs spontaneously in people with risk factors such as tall, body mass index under 19 and male gender. However, a traumatic PNX can be the result of penetrating or blunt trauma (3). The PNX prevalence in cases of blunt trauma is $15-49 \%$ (4). Blast injuries have become more common in the last century causing by terrorist attack events like bomb explosions and home-related or industrial accidents $(5,6)$. The blast injuries of large tires similar to the explosion of landmines have not included chemical or thermal damages (7). While repairing or servicing a large tire, the explosion of the tire may result in high mortality and morbidity. Usually, the patients are young mechanics or drivers $(8,9)$. The main problematic issue is to prevent the people from this kind of blast trauma.

\section{Case Report}

A 37-year-old male patient was admitted to our hospital emergency department (ED) because of blast trauma. The cause of blast injury is that the patient hits the tire with a hammer to check the pressure. As a result of this action, the tire was exploded, and the patient took the blast effect of the explosion directly to his chest. The patient's symptoms were dyspnea and pain in the chest. He has many petechial lesions on the skin of the anterior chest wall and a decrement in breathing sound at the left hemithorax. Thorax computed tomography (TCT) showed hemopneumothorax and seven rib fractures (two of them are separated) at the left hemithorax (Fig. 1a). There were also contusions at the apex of the right lung. In the presence of these findings, the patient underwent tube thoracostomy at the ED (Fig. 1b). The transthoracic echocardiogram examination of the patient revealed no pathology for cardiac problems due to barotrauma. The tube thoracostomy of the patient, who had no air leak and PNX on the third day of hospitalization, was ended (Fig. 1c). The patient's treatment was completed and discharged.

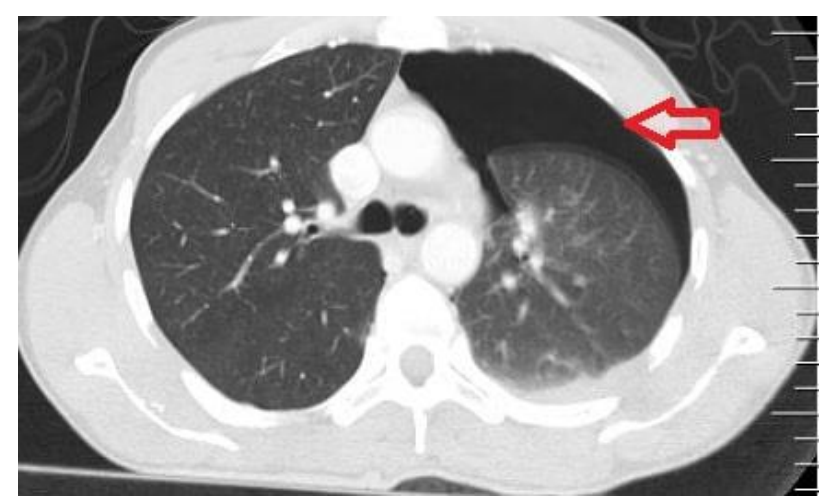

Figure 1a. The TCT scan of patient before tube thoracostomy.

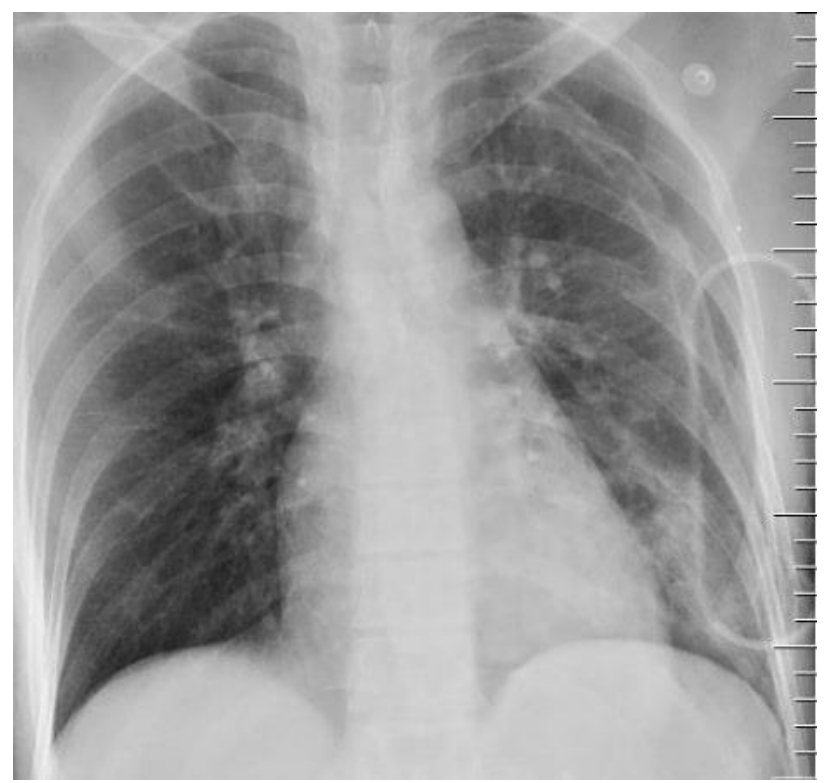

Figure 1b. The chest x-ray of patient after tube thoracostomy.

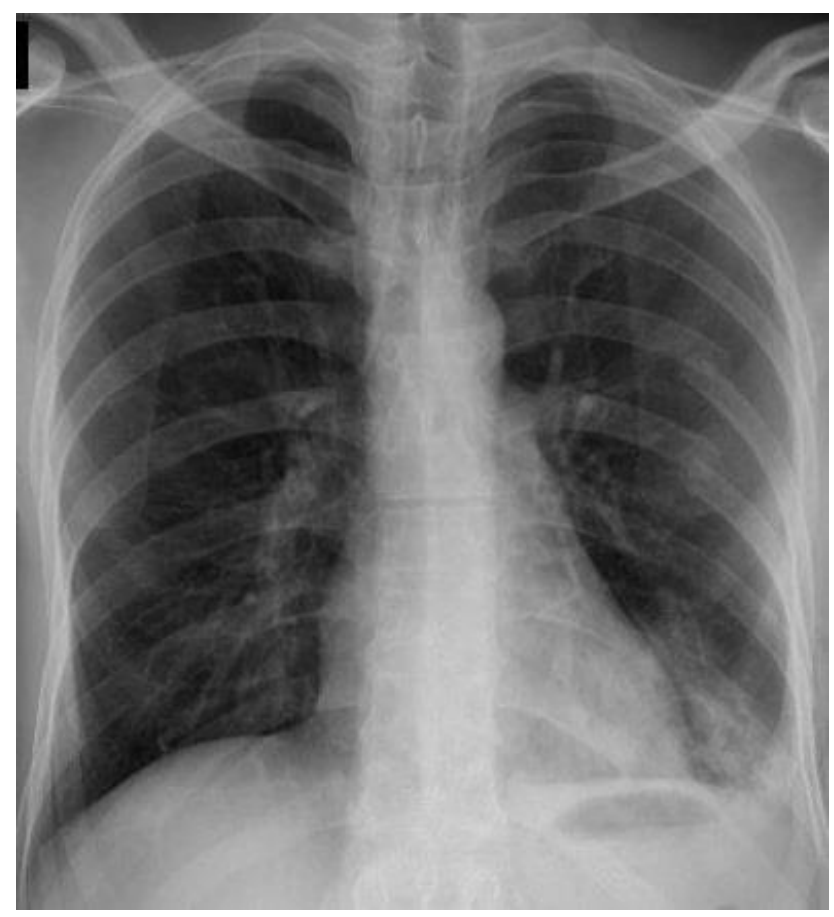

Figure 1c. The final chest $x$-ray of patient after treatment. 


\section{Discussion}

Barotrauma-related PNX is less common than other PNX types like spontaneous or iatrogenic PNX. However, a traumatic PNX can be the result of blunt (bomb explosion, car accident, falling from high in construction areas) or penetrating trauma (gunshots and knife attacks) (3). The ratio of PNX prevalence in cases of blunt trauma is $15-59 \%$ (4). In another study, PNX has detected twenty-five $(11.8 \%)$ of 212 patients with blunt trauma (10) In this case, an interesting and rare cause of barotrauma-related PNX was seen in the ED.

Barotrauma defines the damage that the airline and the alveoli are exposed to. The primary effect of injury is becoming the shock waves. The shock wave shows the most critical effect in the lungs (compare with the other air-containing organs such as nasal sinuses and eardrum) $(11,12)$. That kind of injuries results in PNX, hemothorax, pulmonary contusion and rib fractures (6). In this study, the patient had hemopneumothorax and seven rib fractures at the left hemithorax and contusions at the apex of right lung as seen in the literature.

Blast injuries have become more common in the last century causing terrorist attack events like bomb explosions, and home-related or industrial accidents $(5,6)$. The blast injuries of large tires similar to explosion of landmines but have not include chemical or thermal damages (7). While repairing or servicing a large tire, the explosion of the tire may result in high mortality and morbidity. Usually, the patients are young mechanics or drivers $(8,9)$. Chest traumas are $33 \%$ of the cases hospitalized because of trauma (13). In the first four decades of lifetime, chest trauma composes $25 \%$ deaths because of trauma and the mechanism of the defect is blunt in $70 \%$ of these trauma cases $(14,15)$. In this study, the patient was a 37-year-old male truck driver and compatible with the literature. An explosion of the truck tire injured him while he was repairing it.

Prevention must be the doctors' ultimate target. This aim is the most cost-effective way to reduce the harmful effect of an injury (16). Professional tire servicing or repairing a truck tire with proper equipment are the most significant preventive measures (17). Like in the other literature studies, the patient was not using any protective pieces of equipment during work and got injured because of it.

\section{Conclusion}

Consequently, the large tire blasts constituted the high energy traumas and might cause serious injuries, leading to high morbidity or mortality rates. Especially in our country, increasing the consciousness of this critical problem is essential. Preventive mechanisms must be developed both with the education system and with the law, and they should be used in everyday life routine.

Ethics Committee Approval: Approval was received for this study from the patient.

Peer-review: Externally peer-reviewed.

\section{Author Contributions:}

Concept, Design, Literature search, Data Collection and Processing, Analysis or Interpretation, Writing B.H

Conflict of Interest: No conflict of interest was declared by the author.

Financial Disclosure: The author declared that this study hasn't received no financial support.

\section{References}

1. Lichtenstein D. Novel approaches to ultrasonography of the lung and pleural space: where are we now? Breathe 2017;13:100-11.

2. Light RW, Broaddaus VC. Pneumothorax, chylothorax, hemothorax and fibrothorax. In: Murray JF, Nadel JA, editors. Textbook of Respiratory Medicine. 3rd.Philadelphia: W.B Saunders Company 2000;p.2043-66.

3. Dulchavsky SA, Schwarz KL, Kirkpatrick AW, Billica RD, Williams DR, Diebel LN, et al. Prospective evaluation of thoracic ultrasound in the detection of pneumothorax. J Trauma 2001; 50:201-5.

4. Ozcelik C. Penetrating Chest Injuries. In:Yuksel M, Kalayci G, editors. Thoracic Surgery (The Red Book). 1st edition. İstanbul: Bilmedya Group;2001, s.465-80.

5. Hayda R, Harris RM, Bass CD. Blast injury research: modelling injury effects of landmines, bullets, and bombs. Clin Orthop Relat Res 2004;422:97-108.

6. Pyper PC, Graham WJ. Analysis of terrorist injuries treated at Craigavon area hospital, Northern Ireland, 1972-1980. Injury 1983;14:3328.

7. Blechner MH, Seiler 3rd JG. Tire explosion injuries to the upper extremity. J South Orthop Assoc 1995;4:255-62. 
8. Bautista BN, Kernahan DA, Vistnes LM. Truck tire-rim injury-a new trauma entity. Plast Reconstr Surg 1971;47:117-21.

9. Rautji R, Rudra A, Dogra TD. An unusual fatal injury due to tyre burst: a case report. Forensic Sci Int 2003;138:111-3.

10.Kaya S, Cevik AA, Acar N, Doner E, Sivrikoz C, Ozkan R. A study on the evaluation of pneumothorax by imaging methods in patients presenting to the emergency department for blunt thoracic trauma. Ulus Travma Acil Cerrahi Derg 2015;21:366-72.

11. Matloub HS, Prevel CD, Sanger JR, Yousif NJ, Devine CA, Romano J. Tire explosion injuries to the upper extremity. Ann Plast Surg 1992;29:1113.

12. Obafunwa JO, Busuttil A, Scott C. Fatal compressional injuries from a burst tyre: an industrial death. J Clin Forensic Med 1997;4:17680.

13.LoCicero J 3rd, Matrox KL. Epidemiology of chest trauma. Surg Clin North Am 1989;69: 159.

14.Er M, Işik AF, Kurnaz M, Cobanoglu U, Sagay S, Yalcinkaya I. Clinical results of four hundred and twenty-four cases with chest trauma. UlusTravma Acil Cerrahi Derg 2003;9:267-74.

15. Soysal O. Blunt Chest Injuries. In:Yüksel M, Kalayc1 G, editors. Thoracic Surgery (The Red Book). 1 st edition. İstanbul: Bilmedya Gruop;2001, s.447-64.

16. Barss P, Smith GS, Baker SP, Mohan D. Occupational injuries. In: Barss P, Smith GS, Baker SP, Mohan D, editors. Injury prevention: an international perspective. New York: Oxford University Press; 1998. P. 219-32.

17.Sussman AM, Williams JS, Boyd CR, DeLoach ED. Multipiece tire rim injuries. J Trauma 1991;31:24-7. 